\title{
Home-Based Palliative Care and Aging in Place and Community
}

\section{Palliative Care}

Palliative care provides healthcare and emotional support to those living with a serious illness and their families throughout the course of the illness and often the patient's life. Palliative care is a form of patient-centered long-term care that prioritizes the quality of life of the patient. It is not limited to older adults, but for the purpose of this book, we will focus on palliative care for those 65 and older. Palliative care is designed to treat the whole person, not just their medical concerns. It combines coordinated care management with psychological support for patients and their families as they navigate life with serious illness. Psychological support includes help with stress or depression. Both are critical quality-of-life concerns that are often overlooked in traditional care. Other features of a good palliative care program include around-the-clock access to a clinician, care that is coordinated across multiple specialties, and care that is aligned with the priorities of the patient-including end-of-life preferences. 
The good physician treats the disease; the great physician treats the patient who has the disease. (William Osler Founding Professor, Johns Hopkins Hospital)

Palliative care is a vital component of a well-functioning healthcare system, but access to palliative care is scant throughout the world. Part of the reason for this care gap is the increase in life expectancy. There was an approximate 30-year gain in life expectancy between 1900 and 2000 . This seems like a long time to realize such a gain, but it is almost equal to the gain attained over the preceding 5000 years. ${ }^{1}$ The relatively rapid change has left health systems unable to meet the complex care needs for older adults living with multiple chronic illnesses. The care gap can also be attributed to the fact that people used to die from many diseases that they now are able to live with for decades. Additionally, some of these diseases are increasing in occurrence due to alcohol abuse, smoking, and obesity. The ability to live with many diseases is a brilliant feat of modern healthcare, but it is only beneficial if there is quality of life in the added years. This represents the difference between lifespan and healthspan.

The goal of palliative care is to help people living with serious illness to have the best possible quality of life: in other words, to live as well as possible for as long as possible. (Diane E. Meier)

Estimates claim that in the high-income countries, 69 to 82 percent of people who die would benefit from palliative care. ${ }^{2}$ Some claim that if everyone had access to palliative care, as we understand it today, the lives of 100 million people would be improved. ${ }^{3}$ In 2014, the World Health Assembly established the first global resolution on palliative care. The resolution calls for the World Health Organization and Member States to integrate palliative care as a central element of their health systems with a focus on primary care systems and healthcare delivery in the community and home. ${ }^{4}$

It is imperative that institutions update their medical education and training to prepare students to meet the need for palliative care in all settings. It is long overdue for health providers to adapt to the demographic shift by building lower-cost systems of accessible, coordinated care that 
can serve the older population with high rates of comorbidity. These systems must have the capacity to honor the late life care plan and priorities of each individual. To accomplish palliative care penetration on the scale needed, we must adjust our collective vision from a medicalized cure mentality to one of care and support.

We are increasingly moving away from fee for service because of the recognition that it is bankrupting our society and it is not meeting the healthcare needs of patients and families. (Diane E. Meier)

\section{Cost Outcomes of Palliative Care}

Five percent of the most ill patients living with multiple chronic conditions and functional limitations account for 60 percent of the total cost of healthcare in the US. ${ }^{5}$ Eighty-nine percent of this population will live for more than a year. ${ }^{6}$ Palliative care not only enables a better quality of life for people living with illness and their families, but it is value-based care that can substantially lower healthcare costs. This savings is most effective when care is delivered in the home setting. It is possible to take care of three people in their home for the same cost as keeping one person in a long-term care residence. ${ }^{7}$ When care is coordinated across the continuum, it is more efficient and reduces redundancies, medical error, unnecessary care, length of hospital stays, hospitalizations, emergency department visits, overall healthcare utilization, patient depression and pain, and conflicting care and medications. ${ }^{8,9}$

Overtreatment and overtesting raise healthcare costs for insurers and also for the patient and their families. In the US, overtreatment results in each household paying thousands of dollars out of pocket for unnecessary care each year. ${ }^{10}$ Not all families can bear the brunt of the costs without compromising on other important spending such as food, education, and their own healthcare. This drives an increase in the social determinants that lead to poor health, which eventually costs the healthcare system more in the long run. It should be noted that out-of-pocket costs impact lower-income households more strongly than medium- and upper-income households, thus perpetuating a cycle of poverty. 
Hospitals should be the place of last resort, not the only resort. (Diane E. Meier)

Emergency department visits, hospital readmissions, and care transitions are reoccurring themes in this and other chapters because all markedly increase the cost of care and do not necessarily contribute to better health or quality of life for older patients. Palliative care provides patients with access to medical support around the clock. The access to care clinicians after hours gives patients better options than an ambulance transport and emergency department visit for health crisis that could have been avoided with coordinated accessible care or could have been treated at home by a caregiver, family member, or the palliative care team. Palliative care teams are trained to anticipate predictable health complications and prepare for them in advance by monitoring specific symptoms and health measures. Dr. Kristofer Smith and his team at Northwell Health also stock medications and medical equipment in the home in preparation for predictable adverse health events that can be handled by a family member or caregiver. This helps patients avoid the cycle of emergency department visit, subsequent hospitalization, care transition to skilled nursing, and care transition to the home.

Medical errors are the third leading cause of death in the US. ${ }^{11}$ Hospitals and emergency departments are dangerous and expensive environments for older frail people who are cognitively and immunologically vulnerable. These settings can cause infection, confusion, delirium, and falls, which increase the care costs and care need. The accompanying health decline can often lead to the patient transitioning to expensive skilled nursing care before they make it back home, if they do make it home. This cycle causes suffering and is remarkably expensive.

As we mentioned in Chap. 1, 80 percent of people prefer to die at home, while few do. This is because there are not systems in place to honor the desire to age in place and die at home. Dying in a clinical setting is also far more expensive. People who die in the hospital incur costs that are seven times that of those who die at home. ${ }^{12}$ Throughout the end-of-life process, many people receive overtreatment and unnecessary and even harmful care. End-of-life care planning and systems that support the wishes of the patient and the family can help people avoid unwanted, invasive care and generate substantial cost savings. 
The 1997 seminal report by the Institute of Medicine (IOM), Approaching Death. Improving Care at the End Of Life $e^{13}$ shined a groundbreaking spotlight on the suffering caused by too much costly care at the end of life that neither improves quality of life nor extends the length of life. Since its publication, and the 2014 publication by the IOM, Dying in America: Improving Quality and Honoring Individual Preferences Near the End of Life, ${ }^{14}$ awareness has increased and palliative care has become more available for all life stages, but the response still falls exceedingly short of the need.

\section{Patient Engagement and End-of-Life Care}

Palliative care falls under the umbrella of person-centered care because it is based in individualized coordinated care that is designed to meet and adapt to the changing priorities of the patient. This includes advanced care planning that involves soliciting, understanding, and honoring how and where the patient wishes to live out the last months of life. Advanced care planning is an invaluable element that helps to meet the goal of wellbeing for older people living with advanced illness. Honoring the end-oflife preferences of the patient is important from a human standpoint and is also financially impactful.

Atul Gawande, MD, MPH, ${ }^{15}$ advocates for care systems that are designed to honor the priorities of the patients throughout the end of life. He is the author of four New York Times best sellers including Being Mortal: Medicine and What Matters in the End. In his testimony before the US Senate Special Committee on Aging for the hearing entitled "The Right Care at the Right Time: Ensuring Person-Centered Care for individuals with Serious Illness," ${ }^{16}$ Gawande stressed the need for physicians to have discussions with their patients about their care priorities. He noted that these important fact-gathering conversations occur less than one third of the time before a person's death, resulting in care that does not align with what is most important to the patient.

Gawande also noted that when care aligns with a patient's priorities, people feel more in control, they experience less anxiety and depression, and they spend more time at home and with family. Additionally, patients 
often live longer. ${ }^{17}$ Usually, when asked, many people will opt out of invasive procedures and medications that are not life-saving and often do not prolong a life of any quality. Procedures that focus more on disease control than quality of life do not even help people live longer. They cause more suffering; patients experience more pain, more anxiety, more unnecessary care, and more hospitalizations. ${ }^{18}$

Despite this knowledge and efforts by insurers and health systems to meet the need of palliative care for the increasing older population, a considerable care gap still exists today. This gap is most prominent in the community setting, which is any setting that is not the hospital including office practices, cancer centers, dialysis centers, nursing homes, assisted living facilities, and care in the home.

Hospitals with palliative care programs have resulted in shorter lengths of stays, fewer intensive care admissions, and lower laboratory and pharmacy costs. ${ }^{19}$ On a more hopeful note, due in large part to the efforts of Dr. Diane E. Meier and the Center to Advance Palliative Care, the number of hospital-based palliative care programs in the US has more than tripled in the last decade. Today, in the US, 70 percent of hospitals with more than 50 beds have a palliative care team. This is a promising advancement that we hope will continue to expand and progress in hospitals nationally and around the world.

The Center to Advance Palliative Care is leaping into the quality chasm facing those living with serious illness, and trying to close it. (Diane E. Meier)

\section{Dr. Diane E. Meier, The Center to Advance Palliative Care}

Diane E. Meier is the Director of the Center to Advance Palliative Care (CAPC). ${ }^{20}$ She is also Vice Chair for Public Policy, Professor of Geriatrics and Palliative Medicine, and the Catherine Gaisman Professor of Medical Ethics at the Icahn School of Medicine at Mount Sinai in New York City.

The Center to Advance Palliative Care is an international non-profit organization within the Icahn School of Medicine at Mount Sinai. The Center fosters the awareness and integration of palliative care programs in 
all care settings. CAPC serves as a resource for education, training, tools, and technical assistance. It is an organization with 900 healthcare provider members. CAPC has designated 11 Palliative Care Leadership Centers around the country that educate and train organizations planning to develop sustainable palliative care programs. The Center also houses a directory of palliative care providers in the US. CAPC acts as a think tank and a convener of thought leaders to distill best practices into transferrable skill sets and share the information. Diane refers to this practice as the facilitation or diffusion of innovation.

We have a healthcare system that was designed 65 years ago our around curable, fixable, and surgical problems. It fails to address the whole person care needs of the tens of millions of people with serious and often multiple chronic illnesses who are living a long time.

\section{Patient Priorities}

A palliative care team has an ongoing conversation with their patients to understand their changing life priorities. These priorities are weighed against the outcomes of procedures and the side effects of medications. This is a variation on the theme of risk surplus that we described in the Allan Power section of Chap. 1. It also echoes the patient-centered longterm care philosophies from the same chapter. Diane explains the situation that she faces with her patients:

When I ask patients and families what is most important, I will hear answers such as, 'I want to leave the hospital and go home to my garden'. Patients also say, 'I want to see my youngest grandson graduate from college' or 'I want to connect with my brother whom I have not spoken to in thirty years'. I have never had someone say to me, 'I want to live forever'. Yet, the entire healthcare system is designed as if everyone wants to live forever. The factors that matter most to patients and families are completely ignored because we don't ask. How could we possibly design a person-centered care plan without the key concerns of the patient in the forefront? 
Palliative care in the form of hospice is care and support in the last six months of life. Although it is widely available, due to poor patient management and regulations, 30 percent of those who receive hospice in the US receive it for only one week. The national median length of hospice stay is only 17.4 days. ${ }^{21}$ Another barrier to patients transitioning to hospice care is the Medicare requirement that two doctors state the patient is likely to die in a short time. These predictions are not easy or reliable so physicians often do not make them. Without the support of hospice, patients often fall victim to the cycle of home, emergency department, hospitalization, and skilled nursing throughout their last couple of months of life.

Diane shared a New York Times article that documented this far too common cycle caused by the inability of the healthcare system, as it is structured today, to honor people's preferences. In the article, Fighting to Honor a Father's Last Wish: to Die at Home, ${ }^{22}$ author Nina Bernstein recounts the heartbreaking and unsuccessful efforts by a daughter to honor her father's care plan in the last two years of his life. The article is a perfect example of what most seniors experience in the last two years of life. The comments by the readers expressed outrage. Many people who commented had similar life experiences themselves. It is Diane's belief that people, as healthcare customers and stakeholders, will become a driving force in the expansion of more accessible palliative and late life care.

\section{Education and Training}

Physicians and other members of the palliative care team are trained to offer emotional support to their patients and their families. They are skilled in symptom management including fatigue, depression, and difficulty sleeping. Family members, who are often seniors themselves, also experience these symptoms. They feel overwhelmed with the task of managing a serious illness. They might have had to leave the workforce. They are living with the fear of losing their family member. They are likely facing the financial ramifications of out-of-pocket costs and lost employment.

Diane reminds us of the daunting education gap within the professional community. She asserts that palliative care training and education should be a prominent part of every medical school, nursing program, 
and all other clinical care education programs. When medical education is solely focused on curing an illness, symptom management is not given enough educational and training attention. Doctors and nurses need symptom management expertise because many symptoms of chronic illness such as pain, nausea, exhaustion, depression, stress, and others will last throughout the lifetime of a patient. Additionally, all clinicians need to be trained in how to have the conversations to learn what is most important to the patient and family, and how to navigate and document these discussions to build a patient-centered care plan.

Hofstra Northwell School of Medicine ${ }^{23}$ is an example of a medical school that designed a curriculum to prepare physicians to thrive in the new era of medicine with a focus on aging care and community-based delivery. Other medical schools are using the CAPC education programs in a flipped classroom style where the students study online and use classroom time to practice palliative care skills and review case studies.

\section{Palliative Care at Home}

Diane explained that most homecare is provided by home health agencies that are not delivering primary or palliative care. CAPC and other palliative care advocates are encouraging payers, including Medicare and Medicaid, to reimburse for palliative care in the home. Dr. Kristofer Smith has been making house calls for 15 years. His commitment to delivering the right care at the right time and in the right setting continues today at Northwell Health Solutions.

Healthcare is finally understanding that the house call is not a nostalgic nod to the past but rather an essential care model for those who are most vulnerable. (Dr. Kristofer Smith)

\section{Dr. Kristofer Smith, Northwell Health Solutions}

Dr. Kristofer Smith is the Senior Vice President of the Office of Population Health Management and the Medical Director for Northwell Health Solutions, the largest integrated health delivery system in New York State. 
He is also an Associate Professor in the Department of Medicine at the Hofstra Northwell School of Medicine. The Center to Advance Palliative care designated Northwell Health Solutions a Palliative Care Learning Center. This offers Kristofer and his team a structured way in which to teach their palliative care models to organizations around the world.

As part of their commitment toward value-based care that meets the triple aim of lower cost, better outcomes (including patient satisfaction), and increased access, the Centers for Medicare and Medicaid Innovation (CMMI) funded a 15-site demonstration project named Independence at Home. ${ }^{24}$ The goal of the demonstration is to determine whether a primary care program can yield value-based outcomes for Medicare patients with multiple chronic conditions and cognitive and functional impairments. The program is considered home-based palliative care because primary care and palliative care are one in the same for this patient population. Nine of the 17 participating sites realized over US\$25 million in savings in the first year of the demonstration. ${ }^{25}$ In year two, the demonstration served over 10,000 patients and saved Medicare over US\$10 million, representing an average US $\$ 1010$ per beneficiary. Seven of the participating practices will share in incentive payments totaling US\$5.7 million. Centers for Medicare and Medicaid (CMS) also measured the quality outcomes of each demonstration site. All of the providers showed quality improvements in at least two measures, while four practices showed improvement in all measures. ${ }^{26}$ The measures include:

- Provider makes contact with the patient within 48 hours of hospital admission, hospital discharge, or emergency department visit;

- Patient has fewer hospital readmissions within 30 days;

- Provider identifies a patient's medication within 48 hours of hospital discharge;

- Provider documents the preferences of the patient;

- Provider uses inpatient hospital and emergency departments less often when treating conditions such as diabetes, high blood pressure, asthma, pneumonia, and urinary tract infection.

Northwell Health Solutions serves approximately 1400 patients each year in their home-based primary care division. ${ }^{27}$ A subset of 
approximately 350 to 400 of those patients participate in the Independence at Home demonstration. The mission of the homebased primary care program is to:

- Provide patient- and family-centered care;

- Maintain or improve functional capacity;

- Reduce unwanted and unnecessary care;

- Increase the days a patient spends in their home;

- Facilitate death with dignity at home.

My job is to understand how to make all the programs in between hospice and regular ambulatory care self-sustaining financially.

\section{Population Health}

Kristofer Smith and his team identify the frailest patients who need a better healthcare option. This population is often cycling from home to hospital to skilled nursing and back home. They are receiving care in the least optimal settings while realizing poor outcomes and poor quality of life. Kristofer and his team bring these individuals a higher intensity person-centered care model that is tailored to the priorities of the patients and their families. The care plan is dynamically aligned with the patient's changing health status. This program fills the two-year, on average, care gap between ambulatory and hospice care (Fig. 5.1). Home-based primary care would not be financially sustainable under a fee for service reimbursement model. It has only been made possible in recent years since the passage of legislation in support of value-based care and the resulting alternate payment models. This reimbursement evolution presents better opportunities for providers to meet the care and support needs of their older population.

The average age of the patients in the home-based primary care program is 86. Sixty-three percent need assistance with five to six activities of daily living. ${ }^{28}$ They have a median survival rate of two years, which means they do not yet qualify for hospice. They are two thirds female. They are living with illnesses that are so advanced that it is difficult for them to leave their homes and travel to ambulatory practices. 


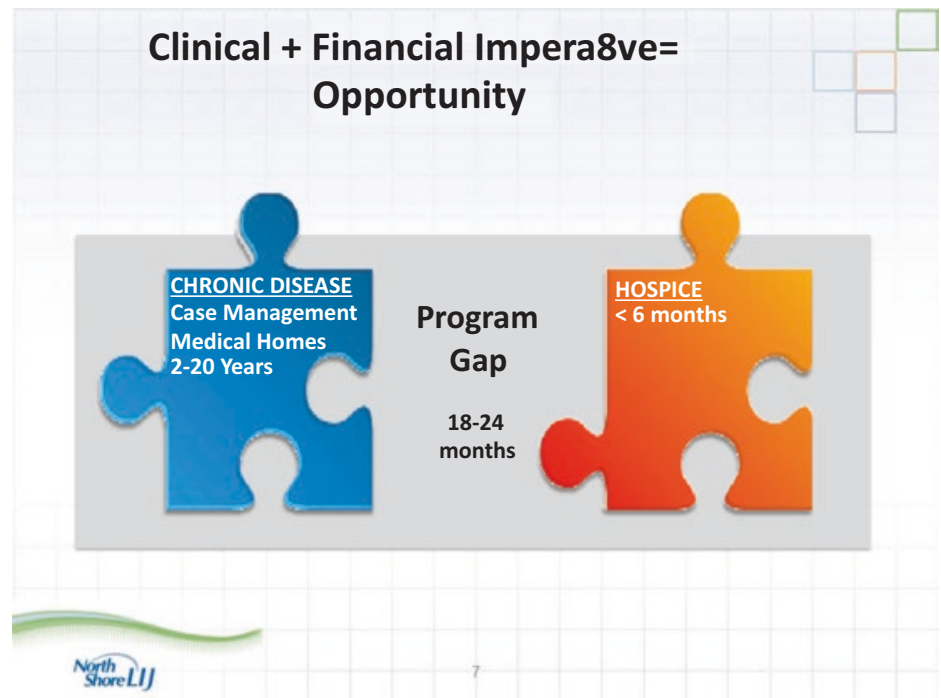

Fig. 5.1 Palliative care gap

Our patients are usually older, frail, and have multiple chronic conditions. We titrate the intensity of the care model for patient.

\section{Challenges to Home-Based Palliative Care}

One of the challenges of the home-based primary care program is making sure that patients are in the right program. If a lower-cost patient is placed in a higher-cost program, the opportunity for cost savings is lost. The home-based primary care program of Northwell Health Solutions costs US $\$ 4000$ per patient per year. If a high-cost patient enters that program, the opportunity for cost savings is substantial and can make the program self-sustaining.

Another challenge that home-based primary care presents is convincing the patients and their families to call the care team when they experience a health crisis. Patients and families are accustomed to dialing 911 when they are in distress. They have not had any other option for their whole lives. Kristofer discussed the need for the care team to build trust 
with the patients and their families. The around-the-clock availability decreases emergency department visits and readmissions and keeps their patients out of the cycle of dangerous care and in their homes instead. The program is fundamentally about the reduction of suffering.

The providers of the home-based primary care coordinate all of the care of the patient to avoid care fragmentation. The program uses a team consisting of medical coordinators, physicians, nurses, social workers, and nurse practitioners. The physicians make 110 house call visits per month. The frequency of the other team members depends on the care needs of the patients. This type of home-based primary care would be difficult for a smaller provider organization to offer because of the need for a highly trained care team and the administrative infrastructure to measure outcomes and monitor the changing health profiles of the patients.

\section{Pending Legislation and New Payment Models}

Kristofer and his team at Northwell Health Solutions and the other successful Independence at Home providers have been so successful in delivering higher-quality care outcomes at a lower cost that, in July of 2016, bipartisan party ${ }^{29}$ introduced legislation ${ }^{30}$ to make Independence at Home a permanent benefit within the Medicare program. Additionally, Kristofer, as part of the model design team with the Coalition to Transform Advanced Care (CTAC), recently received a support from Medicare's Physician-Focused Payment Model Technical Advisory Committee to implement a community- and home-based palliative care model for Medicare Fee-For-Service patients. It is our hope that this happens and that community-based palliative care becomes the normal standard of care.

\section{Aging in Place and Community}

Home-based palliative and primary care enables aging in place. Approximately 90 percent of older adults want to stay at home throughout the course of their lives. ${ }^{31}$ Aging in community is a concept based in 
the understanding that simply being able to stay in one's home is not enough, and that people need personal and societal connections. For the last 30 years, Dr. Allan Teel has been facilitating aging in place with a strong community connection component.

\section{Dr. Allan Teel, Full Circle America}

Dr. Allan Teel is the founder Full Circle America and the author of Alone and Invisible No More. As a home healthcare visionary, he has been enabling his older, frail patients to receive palliative care and support in their homes for the past 30 years. His high-tech, high-touch approach makes use of advanced technology and preexisting community supports and services to build a comprehensive circle of care and social support. The care plan is managed in partnership with the client's existing clinical team.

\section{Technology}

Allan uses the business-to-business facing Bliss CONNECT technol$\mathrm{ogy}^{32}$ to coordinate care and community supports for his clients. After his Sloan MIT fellowship, Pankaj Khare spent seven years designing a coordinated care platform that enables healthcare at home, aging in place and community, long-term care, and disability support. The platform is fully customizable and is device agnostic. The Full Circle America Bliss CONNECT mission is to operationalize an affordable, support solution with an eye on population health while paying attention to some of the healthcare metrics they designed. Their main focus is putting older adults and their families at the center of the healthcare ecosystem.

The technology can be loaded onto a basic user-friendly tablet. The platform home page is much like a social networking site. Users are able to chat and share photos in a Facebook style communication board, send and receive emails, and connect to any outside internet sites. The user can add an endless array of apps, which are customized to their preferences, to the home page for convenience. 
With a finger tap, the user is able to videoconference, teleconference, and e-chat with their care team. The care team includes a doctor, a nurse, a case manager, and all others involved in the older adult's, care including family, neighbors, and volunteers. The complete medical, health, insurance, and billing records are stored in real time on the platform. The program also has panic call and medicine reminder options.

Passive and active video monitoring devices along with motion sensors can be connected through the tablet and sent directly to the care team to be stored on the platform.

Early on, it became crystal clear to me that neighbors and friends had to be a big part of the solution.

\section{Community Assets}

One aspect that makes Full Circle America successful and better than some home care providers is that Allan addresses not just the physical needs of his patients, but he cares for the whole person and finds ways to support their psychological, social, and environmental needs by connecting his patients to their own community assets. Allan believes strongly in the importance of combining healthcare and social supports under one roof. If the patient needs home modifications to be able to remain at home and move about the house, he will recommend such installations. Allan mentioned that it is important to involve the community to divide the health and social needs of his patients into smaller pieces because families are often not able to take on all of the additional responsibility. In approximately an hour or two of research, Allan maps the existing supportive social services that are available locally for each of his patients. He begins by looking for volunteers within the social circle of the patient including friends, family members, neighbors, and fellow church members. His next step is to move out into the community to locate volunteer opportunities that fulfill his patients' need for purpose and generativity. ${ }^{33}$ Some patients wish to volunteer in schools, police departments, fire departments, and senior centers. Some volunteer to visit Allan's other patients via telephone or in person, creating strong peer-to-peer support 
relationships. Allan then locates other local supports including, YMCAs, churches, libraries, and schools. These organizations have age-friendly programming and create intergenerational community connections. They are an inexpensive and effective method of addressing loneliness. All of the community connections are housed and accessible on the Bliss CONNECT platform of the patient.

\section{Outcomes}

The outcomes of the Full Circle America model include better access to care, patient satisfaction, and improved quality of life. His model reduces emergency department visits and hospital readmissions. The Full Circle America services average US\$3600 to US\$9600 per year depending on the need. This gives his patients a far less expensive option than moving into assisted living and long-term care communities. Allan occasionally refers to his services as virtual assisted living.

\section{Barriers to Uptake and Implementation of Home-Based Palliative Care}

Lack of knowledge by the public and the healthcare professionals represent a powerful barrier to the use and implementation of palliative care. Seventy percent of Americans reported that they are "not knowledgeable" about palliative care and most healthcare workers think that palliative care and end-of-life care are the same. ${ }^{34}$ Another barrier is that there are not enough healthcare professionals who are trained and educated in palliative care.

For palliative care to be accessible in all care settings, it requires a health system redesign and a more holistic view of elder care. Culture change is an ongoing challenge and barrier within healthcare transformation. Possibly the change will be driven by the stakeholders, but it must be supported by reimbursement policy so that health providers are able to implement programs that are sustainable. 
Reimbursement policy remains a barrier in access to palliative care for many. The Medicare long-term benefit structure is geared to push patients, who are nearing end of life, into hospitalization or skilled nursing rather than hospice care because Medicare will not reimburse the cost of nursing home or assisted living housing expenses. They reimburse only for the hospice care provided. Often people nearing the end of life cannot move home with an older spouse or by themselves while receiving the only periodic hospice care that is reimbursed. Medicaid will reimburse for housing for those they insure who have depleted their savings, but the process for obtaining this insurance is long and complicated and is often not in place soon enough for the patient.

The shift from fee for service to value-based care has opened up many more possibilities for people to remain at home through the end of life, but this is just the beginning of meeting the need. In the six or seven years that the Centers for Medicare and Medicaid Innovation have been conducting demonstrations, none of the models have led to a reimbursement change. The political leadership of the US can profoundly affect the advancement of palliative care access. Many palliative care providers are nervous about what may happen as the Affordable Care Act hangs in the balance. The House and Senate leadership must not allow themselves to be swayed by lobbying entities that will lose money under newer and better models of palliative care. We hope that the above chapter inspires health systems to raise to the call of the motto of the Center to Advance Palliative Care, "Palliative Care Everywhere."

Another way to improve access to care and health outcomes while lowering healthcare spending is coordinated, person-centered, technologyenabled primary care. In the next chapter, we describe the patient-centered medical home and how providers can become accredited by the National Committee for Quality Assurance. We also write about the Veterans Administration's commitment to ensuring that the nation's veterans receive care when and where they need it.

The full interviews referenced in this chapter can be found at this link: www.accessh.org/agingwell. 


\section{Notes}

1. Butler, R. (1987). The longevity revolution. Mt. Sinai Journal of Medicine. 54(1).

2. Gómez-Batiste, X., Murray, S.A., Thomas, K., Blay, C., Boyd, K., \& Moine, S. (2016). Comprehensive and integrated palliative care for people with advanced chronic conditions: An update from several European initiatives and recommendations for policy. Journal of Pain and Symptom Management. 53(3):509-517.

3. Stjernswärd, J., Foley, K.M., \& Ferris, F.D. (2007). The public health strategy for palliative care. Journal of Pain and Symptom Management, 33(5), 1.

4. World Health Organization (2015). Palliative care. http://www.who.int/ mediacentre/factsheets/fs402/en/. Accessed April 2015.

5. The Lewin Group (2010). Individuals living in the community with chronic conditions and functional limitations: a closer look. https://aspe. hhs.gov/system/files/pdf/75961/closerlook.pdf. Accessed April 2017.

6. Kelley, A.S. \& Meier, D.E. (2015). The role of palliative care in accountable care organizations. AJMC.com. http://www.ajmc.com/journals/ evidence-based-oncology/2015/april-2015/the-role-of-palliative-carein-accountable-care-organizations-/P-1. Accessed April 2017.

7. PBS News Hour-Global and regional models for long-term care: Can they work nationally? Solutions for aging with dignity, independence and choice. http://www.thescanfoundation.org/pbs-newshour-globaland-regional-models-long-term-care-can-they-work-nationally-0. 19:09. Accessed April 2017.

8. Smith, G., Bernacki, R.B \& Block S.D. (2015). The role of palliative care in population management and accountable care organizations. $J$ Palliat Med, 18(6), 486-494.

9. Meier, D.E. (2011). Increased access to palliative care and hospice services: Opportunities to improve value in health care. Milbank Quarterly, 89(3), 343-380.

10. Gawande, A. (2015). Overkill. An avalanche of unnecessary care is harming patients physically and financially. What can we do about it? The New Yorker. May 11. http://www.newyorker.com/magazine/2015/05/11/overkill-atul-gawande. Accessed April 2017.

11. Makary, J.A. \& Daniel, M. (2016). Medical error-The third leading cause of death in the US. BMJ. 353: i2139.

12. Kodjak, A. (2016). Dying in a hospital means more procedures, tests, and costs. National Public Radio. http://www.npr.org/sections/health- 
shots/2016/06/15/481992191/dying-in-a-hospital-means-moreprocedures-tests-and-costs. Accessed April 2017.

13. Field, M.J. \& Cassel, C.K. (1997). Approaching death Improving care at the end of life. Institute of Medicine, National Academy Press, Washington, D.C.

14. http://www.nationalacademies.org/hmd/Reports/2014/Dying-InAmerica-Improving-Quality-and-Honoring-Individual-PreferencesNear-the-End-of-Life.aspx. Accessed April 2017.

15. http://atulgawande.com/about/. Accessed April 2017.

16. Ariadne Labs, 2016. https://www.ariadnelabs.org/2016/06/23/read-dratul-gawandes-testimony-before-u-s-senate-special-committee-agingon-serious-illness/. Accessed April 2017.

17. Ibid.

18. Institute of Medicine (2014). Committee on Approaching Death; Addressing key end-of-life issues. Dying in America: Improving quality and honoring individual preferences near the end of life. National Academy Press.

19. Parikh, R.B., Kirch, R.A., Smith, T.J. \& Temel, J.S. (2013). Early specialty palliative care - Translating data in oncology into practice. New England Journal of Medicine, 369(24), 2347-1.

20. https://www.capc.org. Accessed April 2017.

21. National Hospice and Palliative Care Organization. (2015). NHPCO's Facts and Figures. Hospice in America. Pg. 5. https://www.nhpco.org/ sites/default/files/public/Statistics_Research/2015_Facts_Figures.pdf. Accessed May 2017.

22. https://www.nytimes.com/2014/09/26/nyregion/family-fights-healthcare-system-for-simple-request-to-die-at-home.html?_r=0. Accessed April 2017.

23. http://medicine.hofstra.edu. Accessed April 2017.

24. https://innovation.cms.gov/initiatives/independence-at-home/. Accessed April 2017.

25. https://www.cms.gov/newsroom/mediareleasedatabase/pressreleases/2015-press-releases-items/2015-06-18.html. Accessed April 2017.

26. https://www.cms.gov/Newsroom/MediaReleaseDatabase/Pressreleases/2016-Press-releases-items/2016-08-09.htrnon,

C.\&ml. Accessed April 2017.

27. https://www.northwell.edu/about/news/press-releases/medical-housecalls-program-improves-care-lowers-costs-treating-frail. Accessed April 2017. 
28. Activities of daily living include toileting, bathing, dressing, eating, transferring out of bed, incontinence care, meal preparation, housekeeping, and medication management.

29. https://www.markey.senate.gov//news/press-releases/senators-markeycornyn-bennet-and-portman-introduce-bipartisan-legislation-to-makeinnovative-home-based-primary-care-medicare-program-permanent. Accessed April 2017.

30. https://www.markey.senate.gov//imo/media/doc/2016-07-06-MarkeyIAH-BillText.pdf. Accessed April 2017.

31. Farber, N., Shinkle, D, \& Lynott, J., (2011). Aging in place: A state survey of livability. Policies and practices. AARP Public Policy Institute and National Conference of State Legislatures Research. Report number 2011-13. https://assets.aarp.org/rgcenter/ppi/liv-com/aging-in-place2011-full.pdf. Accessed April 2017.

32. https://blissconnect.com/bliss/. Accessed April 2017.

33. Whitbourne, S.K. (2013). The joys of generativity in midlife. The Huffington Post. http://www.huffingtonpost.com/susan-krauss-whitbourne/generativity_b_2575916.html. Accessed April 2017.

34. Parikh, R.B., Kirch, R.A., Smith, T.J. \& Temel, J.S. (2013). Early specialty palliative care--Translating data in oncology into practice. New England Journal of Medicine, 369(24), 2347-51.

Open Access This chapter is licensed under the terms of the Creative Commons Attribution 4.0 International License (http://creativecommons.org/licenses/ by/4.0/), which permits use, sharing, adaptation, distribution and reproduction in any medium or format, as long as you give appropriate credit to the original author(s) and the source, provide a link to the Creative Commons licence and indicate if changes were made.

The images or other third party material in this chapter are included in the chapter's Creative Commons licence, unless indicated otherwise in a credit line to the material. If material is not included in the chapter's Creative Commons licence and your intended use is not permitted by statutory regulation or exceeds the permitted use, you will need to obtain permission directly from the copyright holder.

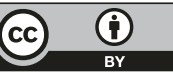

